\title{
Research on the Application of Virtual Reality in Mass Communication
}

\begin{abstract}
Xiaoxue Jin
School:University of Edinburgh

School address: 57 George Square, Edinburgh, EH8 9JU, U.K.

E-mail address:s2052757@ed.ac.uk

ABSTRACT

Virtual Reality technology has become a new industry, and people began to pay great attention to it in the 20th century. VR can be applied to entertainment, medicine, science and other fields. At present, VR technology has different advantages and disadvantages in different fields. This paper studies the advantages and disadvantages of the current technology by analyzing the experience of VR technology in different fields. The development and popularization of Virtual Reality technology is of great significance. It has changed the boring and passive way of communication between human and computer, and made the interaction between human and computer more humanized. Although technology is deeply embedded in people's lives, virtual technology currently has both advantages and disadvantages. The application of analytical technology can be viewed more objectively and continuously optimized in future research and development.
\end{abstract}

Keywords: virtual Reality, application, devices, technology

\section{INTRODUCTION}

Virtual Reality denotes a computer-generated simulation that allows creating of a life-like virtual environment. It is an immersive technology that has the power of creating a perceptual illusion of being present in a virtual environment[1]. Correspondingly, a user can interact in the artificial environment through electronic devices combined with other output devices such as goggles designed with a screen. Virtual Reality uses real-life data obtained from electrical signals to immerse the user in the virtual environment. For example, Virtual Reality can allow one to be immersed in a video game and feel like one of the characters. Virtual technology has become a hot topic in the field of information. It is a multi-disciplinary integrated technology that develops rapidly at present and has influenced people's way of life. This paper analyzes the application of technology in different fields and its advantages and disadvantages in application. This paper also reflects the practicability and humanized design of VR technology. By analyzing VR technology, it is found that its advantages and disadvantages in application. The use of this technology in education, entertainment, medicine, military and other aspects will bring greater benefits to society and people's lives. By analyzing its shortcomings, people can identify the parts that need to be improved for technical improvement and enhance people's sense of use.

\section{ADVANTAGES OF VIRTUAL REALITY IN MASS COMMUNICATION}

Virtual Reality is slowly becoming an integral part of everyday reality, and mass communication is no exception. Arguably, the use of high-rated Virtual Reality in mass media has sparked some significant perks in this sector. Firstly, VR can be used in mass media for virtual storytelling that would otherwise be a significant narrating challenge. Virtual Reality storytelling has wholly transformed journalism by bridging the gap between the emerging world of VR and classical storytelling.[2] For example, Waves of Grace short VR film centered on a survivor of the 2014 Ebola outbreak in Liberia. The Virtual Reality experience places the audience at the heart of the adversely affected communities during the epidemic. Undeniably, Virtual Reality is slowly being incorporated into mass communication as an effective form of story narration. 


\subsection{VR enhances the audience experience}

The sense of presence brought by Virtual Reality affords the users unprecedented access to the sounds and sights and even emotions and feelings that are an essential accompaniment to the news. Immersive journalism in VR headsets is becoming more mainstream and much-touted for inducing a greater presence than the traditional texts [3]. Unlike in the past when the viewers were just onlookers, the audience can currently experience happenings across the globe from a first-hand perspective. The aforementioned can be attributed to immersive journalism enabled by VR. Additionally, researchers have suggested that viewers can retain more information and apply what they have learned in other situations through Virtual Reality. That is the power of Virtual Reality and it is why immersive journalism has added an extra dimension to reporting, making the news more memorable and impactful.

Virtual technology has made it possible for journalists to connect the audience with critical topics and evoke empathy. The above-mentioned can be attributed to the immersive nature of VR. Research done by Yan and Lv established that user intention expression efficiency was high in immersive Virtual Reality social systems.[4] The use of this immersive technology in mass communication brought an opportunity for audience engagement with media texts in a more effective way than traditional methods. Arguably, Virtual Reality can elicit greater empathy, especially on crucial topics, making it easier to deliver the intended message with fewer interruptions. Journalists can now engage with the audience better and deliver the important messages at ease unlike in the past where drawing viewers' attention was seemingly a mindnumbing task.

Arguably, Virtual Reality in mass communication creates an opportunity to engage the audience and evoke much-valued feedback. According to Lindell and Thatte , growing interests in Virtual Reality have prompted 360 media platforms. [6]For example, in 2017, Facebook CEO Mark Zuckerberg released showing abilities of Facebook Virtual Reality headset. The Facebook VR feature allows users to virtually travel to new locations and engage others through virtual headsets. The video is an excellent example of the utilization of VR as a combination of journalism and reporting. Their immersive qualities have been integrated into Facebook spaces. Consequently, the video released by Zuckerberg provoked massive reactions from Facebook users. They criticized VR's strength in evoking emotions through stimulating experiences as a distraction from actual experiences. The ability of Virtual Reality to evoke feedback from the audience is an added advantage to media outlets.
Virtual Reality is an important supplemental material for media communications. The possibility of films and television programs being wholly integrated into Virtual Reality is yet to be termed imminent. However, media organizations are using Virtual Reality to create compelling supplemental material such as building brand recognition and keeping the audience engaged. The audience is interested in the stimulating environment that hosts the television program that they fancy or they can be applied in films to become virtual guests. In the modern era of seeking to create cinematic universes, Virtual Reality is a tremendously compelling supplement.

\subsection{VR technology is used in legal matters}

VR can meet people's psychological needs in life. When people feel stressed and tired during work and study, they can use VR to achieve whatever situation they want to see and feel relaxed, thus relieving people's psychological pressure. Virtual Reality technology can help kids get rid of their fear of getting an injection. Before the injection, the nurse will put the child on a VR screen and let them watch the built-in animation to relax their nerve. The main characters of the cartoon are children who are about to be vaccinated. At the same time, the nurse will begin wiping the alcohol and gently administering the vaccine. In the relaxed atmosphere, the child will not cry, and feel a little proud of completing the originally difficult task of injecting. In the face of some children who are afraid to go to the hospital or get an injection, they will cry. VR technology will help doctors or parents manage their children's emotions, complete the task of injection quickly and effectively, and help doctors reduce some unnecessary troubles. In addition,VR technology can also be used in legal cases. Witnesses in the court will review the crime scene through VR technology, helping the judge, the defendant and the audience see the restored virtual scene directly and clearly, reducing some tedious and unclear multiple times, more effective and pose fair sanctions on the perpetrators.

\subsection{Game entertainment enhances the sense of experience}

In terms of games and entertainment, the use of VR technology can improve people's personal experience, bring them the feeling of being on the scene, and increase their love and satisfaction. People are no longer satisfied with viewing the game world through a specific window, they need a visual and audio track around them. Games are also much more immersive than they were a few decades ago, making it easier to engage with the story and experience the virtual world. Research has shown that VR enhances empathy, and with the right content, people are more able to express respect. This effect does not stop with Virtual Reality 
itself. Changes in mood can extend to reality as well, and content creators can use this effect to convey positive meaning.

\subsection{VR applications help patients relieve pain}

Medicine is not about curing diseases -- at least so far, VR doesn't cure any diseases, but it does offer hope and comfort, more or less, but all of them valuable. When patients need to endure the pain of chemotherapy and fight pain, using VR can create a more comfortable scene for patients. Many seriously ill patients feel anxious when they cannot leave their wards and even send out requests to doctors to go somewhere. Using VR, they can see anywhere they want to go, and even help the gravely ill fulfill their last wishes. These patients' anxiety levels all decreased after using VR, and while this may not be symbolic of a reduction in their symptoms, it is also priceless.

\subsection{The use of VR technology has promoted the development of the news media industry}

VR unquestionably served as an essential role in fueling the rise of robot journalism. Accordingly, robotic journalism is already enhancing performance and productivity for media companies and individual journalists. Similarly, in robot journalism, news articles are generated by computer programs. On the other edge, Virtual Reality innovations offer a tremendous opportunity for news organizations and media seeking more effective methods to convey the news. Accordingly, virtual reality allows them to provide powerful experiences that are vital in conveying the news. For immersive journalism to place the audience at the center of journalistic narrative, virtual is role is immense. The immersive qualities of Virtual Reality have been utilized in robotic journalism.[5] In the latter, computer-generated news articles must be influential and reach the target audience; journalists opt to include some virtual reality qualities.

Virtual Reality is a meaningful way to bridge the gap between journalism, technology, and the future. The aforementioned is grounded on the fact that Virtual Reality is an effective method for media outlets to challenge how they communicate information to their audience. In the past, loopholes existed between journalism, technology, and the future, but Virtual Reality has bridged these gaps. In the current digital era, the role of interactive media technology to minimize the gap between technology and delivering news has been enabled by virtual reality. Media organizations and journalists can now use these immersive technologies to re-engage with the audience. Consequently, the shift towards virtual storytelling has been significant in bridging the gap between journalism, technology, and the future.

\section{LIMITATIONS OF VR TECHNOLOGY}

Although the application of VR does bring convenience to people, there are still some problems in the experience of using the equipment in the development stage of the technology. First of all, it can cause problems such as 3D vertigo and visual fatigue, and virtual reality can affect the nervous system due to the very life-like simulation of movements. While both delays and app design can significantly reduce this, it still happens quite often. Wearing VR for a long time might pull down the face, many devices even do not have a headband design. In addition, the air permeability is also a problem.Virtual Reality systems have another new drawback, they require long wires to connect to a computer or game system. These wires need to be plugged into special signal testing boxes to prevent them from being stretched too far and breaking. But it's still easy to trip over these systems when one is using them in the booths and at work. Sometimes, the wires even get tangled around the legs. In some sitdown entertainment programs, wires are even wrapped around the head, causing the helmet to be skewed and affecting the comfort of the experience.In addition, the price of VR equipment is relatively expensive and cannot be generally accepted by the public. People will only choose to use VR technology for occasional entertainment or special circumstances.

\section{DISCUSSION}

When VR technology is applied to the medical field, it is also a good choice to continuously develop scientific research, to seek solutions to every difficult and complicated disease, and to find a better solution to every simple disease. In terms of engineering design, VR technology can provide a THREE-DIMENSIONAL environment, which enables engineers to easily design their desired designs and greatly increases the design space, so that they no longer have to worry about nowhere to express their ideas, and can also give customers a more intuitive experience. In terms of education, VR technology can be applied to teaching to improve students' enthusiasm, experience degree, communication ability and practical ability, and selfsatisfaction, so as to help them work hard, study hard and make progress. So far, though, VR has some hurdles. It's easy to feel tired and look silly. In the rapid development of science and technology, it is not difficult to overcome obstacles. In the era of Internet spreading all over the world, VR technology will become a trend in the future development, and will become a new star of future scientific and technological development, to enrich life and satisfy personal sense of happiness. 


\section{CONCLUSION}

VR technology can penetrate into various industries and bring convenience to people, but VR technology is not universal in people's daily life, and the capital and volume of VR equipment have not yet been applied to any family or company. There are still some problems in the device's portability and convenience in use, as well as the user's experience when using it. The manufacturing cost of equipment and the development cost of technology affect the price. We need to consider how to use better technology to improve equipment, which can also be quantified, so that more equipment can be adapted to different industries and users can get the support of equipment within the range of affordability.Research on the advantages and disadvantages of VR technology is continuously optimized, improving the shortcomings can make technology truly integrated into people's lives like computers and mobile phones. Through research, it can be found that the future development of VR technology can help people achieve higher benefits in some industries.

\section{ACKNOWLEDGMENT}

The process of writing a paper is hard and boring, but it is also a process of learning. Through continuous exploration and research and searching for relevant materials, I also looked at VR technology from a new perspective and had a deeper understanding. In addition, there is a greater interest in this technology, and I believe this technology will become the mainstream in the future.

I would like to take this opportunity to thank the many people who helped me write this paper. First of all, I would like to thank some teachers who helped me solve my writing problems, especially they led me to think from a professional perspective and explore research from the right direction. Secondly, in the process of writing, this paper has collected a large number of literature materials, and here I would like to express my gratitude to the scholars and experts whose materials are quoted in the text. Finally, I would like to thank my parents, who have been tardy and willing to help me through the hardships of this paper writing process and every moment of my life.

\section{REFERENCES}

[1]Lindner, P. (2020). Better, virtually: the past, present, and future of virtual reality cognitive behavior therapy. International Journal of Cognitive Therapy, 1-24.

[2]Bucher, J. (2017). Storytelling for virtual Reality. https://doi.org/10.4324/9781315210308
[3]Sundar, S. S., Kang, J., \& Oprean, D. (2017). Being there in the midst of the story: How immersive journalism affects our perceptions and cognitions. Cyberpsychology, Behavior, and Social Networking, 20(11), 672-682.

[4]Yan, Z., \& Lv, Z. (2020). The influence of immersive virtual reality systems on online social application. Applied Sciences, 10(15), 5058. https://doi.org/10.3390/app10155058

[5]Soler-Adillon, J., \& Sora, C. (2018). Immersive journalism and virtual reality. Interaction in digital news media, 55-83.

[6]Lindell, D., \& Thatte, J. Virtual Reality Motion Parallax with the Facebook Surround-360.

[7]Sánchez Laws, A. L. (2017). Can immersive journalism enhance empathy? Digital Journalism, $8(2)$, 213-228. https://doi.org/10.1080/21670811.2017.1389286 